Ecological Modelling

September 2016, Volume 335 Pages 35-38

http://dx.doi.org/10.1016/i.ecolmodel.2016.05.007

http://archimer.ifremer.fr/doc/00335/44605/

(c) 2016 Elsevier B.V. All rights reserved.

\title{
Atlantis Ecosystem Model Summit: Report from a workshop
}

\author{
Weijerman M. ${ }^{1,{ }^{*}}$, Link J.S. ${ }^{2}$, Fulton E.A. ${ }^{3}$, Olsen E. ${ }^{4}$, Townsend H. ${ }^{5}$, Gaichas S. ${ }^{6}$, Hansen C. ${ }^{4}$, \\ Skern-Mauritzen M. ${ }^{4}$, Kaplan I.C. ${ }^{7}$, Gamble R. ${ }^{6}$, Fay G. ${ }^{8}$, Savina Marie ${ }^{9}$, Ainsworth C. ${ }^{10}$, \\ Van Putten I. ${ }^{3}$, Gorton R. ${ }^{3}$, Brainard R. ${ }^{11}$, Larsen K. ${ }^{12}$, Hutton T. ${ }^{13}$
}

1 Joint Institute of Marine and Atmospheric Research, 1000 Pope Rd., MSB 312, Honolulu, HI 96822 , United States

${ }^{2}$ National Marine Fisheries Service, NOAA, 166 Water St., Woods Hole, MA 02543, United States

${ }^{3}$ CSIRO Oceans and Atmosphere, GPO Box 1538, Hobart, TAS 7001, Australia

${ }^{4}$ Institute of Marine Research, PB 1870 Nordnes, N-5817 Bergen, Norway

${ }^{5}$ Chesapeake Bay Office, National Marine Fisheries Service, NOAA, 410 Severn Ave., Ste 207-A, Annapolis, MD 21403, United States

${ }^{6}$ Northeast Fisheries Science Center, National Marine Fisheries Service, NOAA, 166 Water St., Woods Hole, MA 02543, United States

${ }^{7}$ Conservation Biology Division, Northwest Fisheries Science Center, National Marine Fisheries Service, NOAA, 2725 Montlake Blvd E, Seattle, WA 98112, United States

${ }^{8}$ Department of Fisheries Oceanography, School for Marine Science and Technology, University of Massachusetts Dartmouth, 200 Mill Rd., Fairhaven, MA 02719, United States

${ }^{9}$ IFREMER, Channel \& North Sea Fisheries Res Unit, 150 Quai Gambetta, BP 699, F-62321 Boulogne sur Mer, France

${ }_{11}^{10}$ University of South Florida, 4202 E Fowler Ave., Tampa, FL 33620, United States

${ }^{11}$ Pacific Islands Fisheries Science Center, National Marine Fisheries Service, NOAA, 1845 Wasp Blvd, Blg. 176, Mail room 2247, Honolulu, HI 96818, United States

${ }^{12}$ Office of Science and Technology, National Marine Fisheries Service, NOAA, 1315 East-West Hwy, Silver Spring, MD 20910, United States

${ }^{13}$ CSIRO Oceans and Atmosphere, QBP, 306 Carmody Road, St Lucia, QLD 4067, Australia

*Corresponding author : M. Weijerman, email address : mariska.weijerman@noaa.gov

\begin{abstract}
:
Ecosystem models can be used to understand the cumulative impacts of human pressures and environmental drivers on ecosystem structure and dynamics. Predictive modeling can show how management can influence those dynamics and structures and the ecosystem services these systems provide. Many nations and intergovernmental organizations are advocating for ecosystem-based management, often with a specific emphasis to evaluate various future management strategies. Atlantis is an end-to-end ecosystem model that is well suited for this task and has so far been developed for more than 30 diverse marine ecosystems worldwide. To provide a better understanding of the current modeling work, elicit wider interest, and foster collaboration within the Atlantis community, the first international Atlantis Summit was convened in December 2015. The main outcomes from this workshop included a clearer framework and infrastructure for model development and collaboration; the opportunity to perform common scenarios with a range of Atlantis models to analyze ecosystem
\end{abstract}


responses to environmental and management-based perturbations; and the use of Atlantis as a test case for exploring the performance of single species, multispecies, and trophic food web models at an international level.

\section{Highlights}

First International Atlantis Ecosystem Modeling Workshop convened in December 2015. It provided an overview of current Atlantis modeling work and fostered collaboration. Atlantis applications have matured as have ecosystem models for use in marine EBM.

Keywords : Ecosystem-based models, Atlantis Summit, Management, Strategy evaluation, Meeting report 


\section{Introduction}

Here we report on the first international workshop that actually begins to operationalize the next paradigm of living marine resource management and the models needed to support it. The application of holistic approaches to ocean management, i.e., Ecosystem-Based Management (EBM) and Ecosystem-Based Fisheries Management (EBFM), is increasingly being advocated for and integrated into marine policy (e.g. Pikitch et al., 2004). This shift in paradigm is partly due to (1) the inefficiency of converting scientific recommendations into practice (Daw and Gray, 2005); (2) traditional exclusion of many ecosystem components (e.g. multi-species interactions, habitat, physical and chemical environments; Skern-Mauritzen et al., 2016), and (3) exclusion of the human dimension in ocean management (Hilborn, 2007). An important component of EBM is the judicious use of ecosystem models co-developed by policy makers, scientists and other stakeholders (Hyder et al., 2015). These models can be used to better understand the complex dynamics of marine ecosystems, to make predictions under various system scenarios, and to evaluate the effectiveness of management strategies taking into consideration socio-ecological tradeoffs (Börjeson et al., 2006). Advocates of EBM often emphasize developing model-based tools and using simulation-based approaches to support management strategy evaluation (MSE), which explicitly models the feedbacks within the adaptive management cycle and allows for uncertainty in the ecosystem and fisheries (Sainsbury et al., 2000). Models used for ecosystem-level MSE should address policy needs, balance socioecological objectives of human activities, and have clear evaluations of trade-offs (Mullon et al., 2015). Human activities perturbing marine systems include more than just fisheries. For example, transportation, marine wind turbines and sea-bed mining are all industries that have increased in recent decades, whereas the relative effects of fisheries have remained mostly stable (McCauley et al., 2015). Therefore, to address the cumulative impacts and benefits of these diverse activities, broad, multidisciplinary, spatially-resolved, process-based models are required.

The Atlantis Ecosystem Model is an ecosystem model that can address all these components in a full MSE context while taking into account fisheries, climate and environmental variability, and multi-sectoral dynamics (Fulton et al., 2011). To date, more than 30 models are in various stages of development (Fig 1) with one model (SE Australia) including a fully-closed MSE loop (Fulton et al., 2014). Many Atlantis models have been developed for temperate marine ecosystems (e.g. Fulton et al., 2007, Horne et al., 2010, Ainsworth et al., 2011), but there are also Atlantis models for polar regions (e.g. Antarctic in development; Arctic, Hansen et al., 2016), tropical coral reefs (Weijerman et al., 2015), estuaries (Chesapeake Bay in development, Condie et al., 2012), lakes (e.g. US Great Lakes and Lake Victoria in development), as well as models that span temperatetropical domains (Hutton, 2012). 


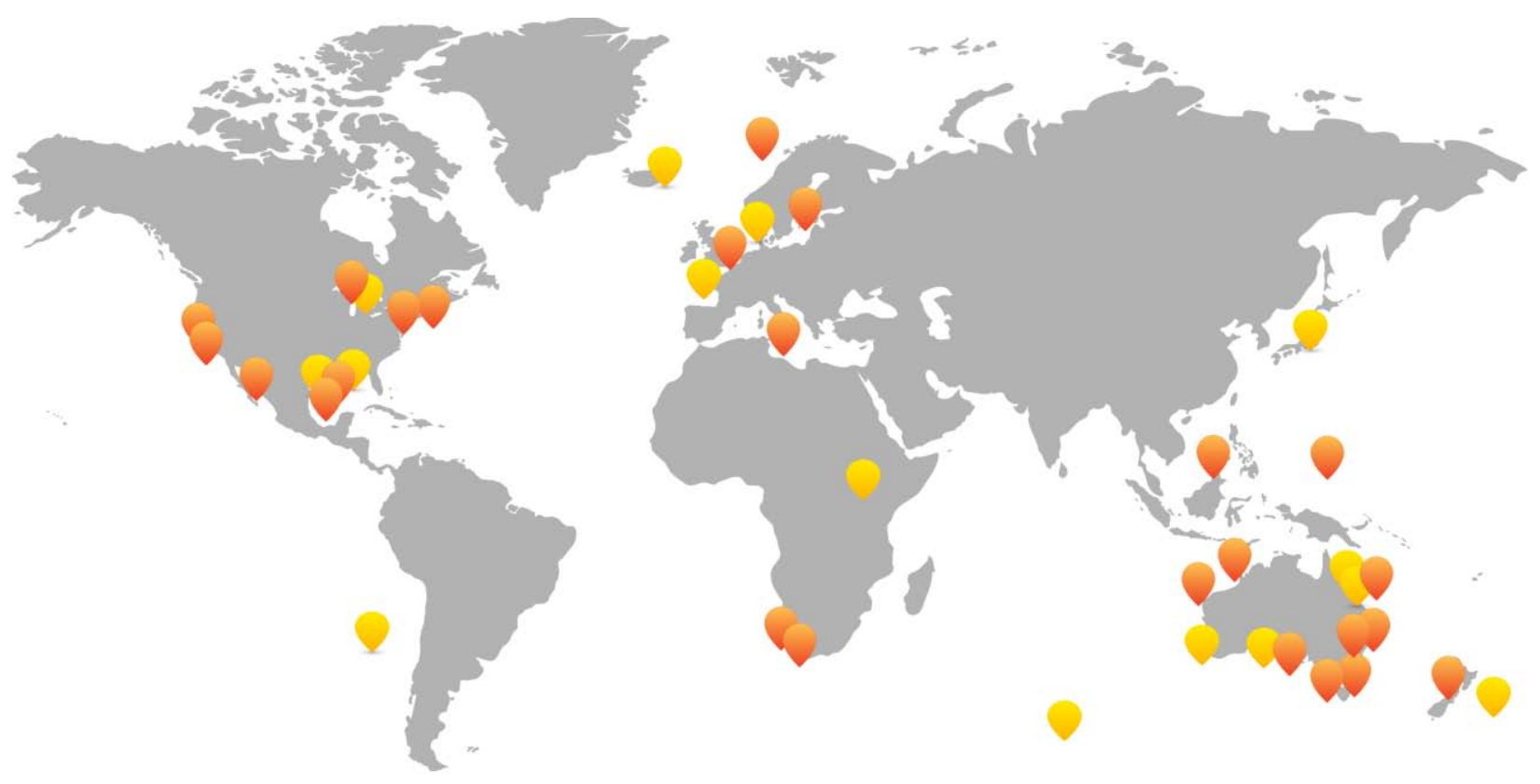

In development Extant

Figure 1. Geographic areas of in-development and extant Atlantis models.

\section{Workshop objectives and approach}

On December 7-11 2015, the first International Atlantis Ecosystem Modeling Summit (http://atlantis.cmar.csiro.au/www/en/atlantis/Atlantis-Summit.html) was convened by CSIRO (Australia), NOAA (USA), and IMR (Norway). The workshop took place in Honolulu, Hawaii, involving 50 scientists from 13 countries. The intention of the summit was to bring together the full community of Atlantis researchers and other interested scientists and managers to consolidate the progress made through the various applications of the Atlantis framework. This consolidation and sharing of experience and knowledge on the various components of the ecosystem models (e.g., coupling of physical and ecological dynamics, inclusion of human dimensions) will provide a substantial contribution to the ecological modeling community. A wide variety of topics was discussed, from both modeling-focused and governance perspectives. Discussion on the role of Atlantis in marine governance included consideration of needs of the International Council for the Exploration of the Sea (ICES) and the U.S. NOAA development of Integrated Ecosystem Assessments (IEAs), and fulfilling the European Union Marine Strategy Framework Directive (MSFD) that mandates participating countries to reach Good Environmental Status (GES) by 2020 (EU Horizon 2020).

The objectives of the workshop ranged from helping nascent Atlantis modeling efforts get up and running to comparing the output of common scenarios simulated by existing Atlantis models developed for different regions and ecosystem types. Specific terms of reference for the workshop included:

1. Provide updates on major Atlantis model modules and parameter sets;

2. Provide updates and lessons learned from Atlantis model applications from different ecosystems; 
3. Identify common best practices for Atlantis modeling;

4. Identify, run, and compare common scenarios from a global suite of Atlantis models to carry out a global analysis of marine ecosystem responses to both perturbations and management actions, thereby illustrating the benefits of integrated EBM over singlesector approaches;

5. Explore means of addressing Atlantis model uncertainty and skill;

6. Discuss lessons learned on the use of Atlantis model outputs in an ocean management context; and

7. Discuss future Atlantis model development.

For each session of the workshop, the aim was to speak on the topic via current examples while simultaneously demonstrating tools and packages, establishing best practices, and identifying relevant synthesis products.

\section{Workshop Outcomes}

A key outcome of the workshop was to create common scenarios that simulate relevant current and future system perturbations that may affect marine ecosystems. The use of ecological indicators and systemic features, particularly germane to the context of the European Union's GES and the United States IEAs for marine ecosystems, were incorporated in these common scenario analyses. To enable these analyses, a set of packages of tools using R (R Core Team 2015) for working with Atlantis output was established. Tools include code for calibration, skill assessment, and visualization of model output for managers and other stakeholders, and have been made freely available online (https://github.com/r4atlantis). Results of these analyses will be disseminated to the wider ecosystem modelling community through publications.

Additional workshop outcomes and a series of products that are at various stages of development are described in Table 1. (Importantly, links and comparisons with other commonly used ecosystem models were highlighted during main plenary sessions with follow-up discussion in small breakout groups.

Table 1. The key themes, associated outcomes, and relevant products of the Atlantis workshop.

\begin{tabular}{ll}
\hline Theme & Outcomes \\
\hline Information & $\begin{array}{l}\text { Creation of a more cohesive Atlantis } \\
\text { community; }\end{array}$ \\
& $\begin{array}{l}\text { Improved organization and access to } \\
\text { information on how to get started with and best } \\
\text { practices for development of various } \\
\text { components of Atlantis }\end{array}$
\end{tabular}

Training Participants were trained on loading and running Atlantis and begin using test models.

\section{Products}

Atlantis wiki

https://confluence.csiro.au/display/

Atlantis/Atlantis+Ecosystem+Model

+ Home+Page), Atlantis google

group

(https://groups.google.com/forum/\#! forum/atlantis-ecosystem-model).

Approximately 10 new users trained.

Planned peer-reviewed paper. Atlantis User Manual under development. Terms of Reference identified. 
model review and performance.

Skill

assessment

Visualization

Novel feature

Development

Communica-

tion

Tools
Methods and applications to explore model skill and sensitivity analysis.

Tools for visualization of Atlantis inputs and outputs.

Exploring and discussing novel features including evolution, pollution, corals, and ocean acidification.

Development of infrastructure to promote collaboration among Atlantis developers.

Created an online repository of relevant tools to aid development and analysis of Atlantis models.
Planned peer-reviewed paper

Demonstration of visual tools e.g. SeaView, (http://www.csiro.au/seaview), VES-V, (https://www.st.nmfs.noaa.gov/ecos ystems/ebfm/ecosystem-modeling)

Ideas for improvement of new model features

Supporting code repositories on github, Atlantis wiki, Atlantis Google group

Links to freely available online $\mathrm{R}$ packages and code:

https://github.com/r4atlantis

\section{Future priorities and opportunities}

Discussions at the workshop also identified areas for future model improvement in the context of policy initiatives (e.g. EU Horizon 2020) that have set deadlines for establishing integrated marine multi-use spatial planning. Examples included better linking of model development and outputs to management and policy where social scientists can play important roles in facilitating engagement with stakeholders to identify and agree on objectives, performance metrics, and key uncertainties for MSE. Another area of improvement is to work more closely with the fisheries stock assessment community to capture realistic processes into Atlantis for MSE. There was recognition of the integrated nature of the challenges facing marine and coastal systems; in that the implementation of EBFM continues to be a significant operational challenge.

Global change, increased human uses, and climate-driven shifts have already and continue to change the oceans' abiotic condition, leading to alterations in biological components of ecosystems (Hoegh-Guldberg and Bruno, 2010). These changes affect the services marine ecosystems provide. Appropriate decision-support tools that can explore the full range of management options are needed. Managers must be able to understand how ecosystems change to adapt their management strategies to mitigate associated negative ecological and societal impacts. Stakeholders benefit from tools that can evaluate the tradeoffs between often conflicting conservation and extraction or human-use goals while accounting for the likely impacts of climate and ocean change. The success of this workshop in creating a global Atlantis modeling community and strengthening these specific tools and products has taken marine science and management a step closer to being able to address the needs for integrated ecosystem-based management. The summit clearly demonstrates a maturing application of the Atlantis model specifically and ecosystem models for use in marine EBM more generally, with a clear and fresh 
exchange of ideas, at a time when such tool development and use cannot come fast enough. Further such exchanges are warranted.

\section{Acknowledgements}

Funding for the workshop came from NOAA Fisheries, CSIRO, IMR and the Norwegian Research Council.

\section{References}

Ainsworth, C.H., Kaplan, I.C., Levin, P.S., Cudney-Bueno, R., Fulton, E.A., Mangel, M., TurkBoyer, P., Torre, J., Pares-Sierra, A., Morzaria Luna, H., 2011. Atlantis model development for the Northern Gulf of California. NOAA Tech.Memo. NMFS-NWFSC110, U.S. Dept. Commer. 293 p.

Börjeson, L., Höjer, M., Dreborg, K.-H., Ekvall, T., Finnveden, G., 2006. Scenario types and techniques: Towards a user's guide. Futures 38,723-739. doi:http://dx.doi.org/10.1016/j.futures.2005.12.002.

Condie, S.A., Hayes, D., Fulton, E.A., Savina, M., 2012. Modelling ecological change over half a century in a subtropical estuary: impacts of climate change, land-use, urbanization and freshwater extraction. Marine Ecology Progress Series 457, 43-66.

Daw, T., Gray, T., 2005. Fisheries science and sustainability in international policy: a study of failure in the European Union's Common Fisheries Policy. Marine Policy 29, 189-197.

Fulton, E.A., Smith, A.D.M., Smith, D.C., 2007. Alternative management strategies for Southeast Australian Commonwealth Fisheries: Stage 2: Quantitative management strategy evaluation Deakin West, ACT. Fisheries Research and Development Corp., 2007.

Fulton, E.A., Link, J.S., Kaplan, I.C., Savina-Rolland, M., Johnson, P., Ainsworth, C., Horne, P., Gorton, R., Gamble, R.J., Smith, A.D.M., Smith, D.C., 2011. Lessons in modelling and management of marine ecosystems: the Atlantis experience. Fish and Fisheries 12, 171188.

Fulton, E.A., Smith, A.D.M., Smith, D.C., Johnson, P., 2014. An Integrated Approach Is Needed for Ecosystem Based Fisheries Management: Insights from Ecosystem-level Management Strategy Evaluation. PLoS One.

Hansen, C., Skern-Mauritzen, M., Meeren, G.I. .v.d., Jähkel, A., Drinkwater, K., 2016. Set-up of the Nordic and Barents Seas (NoBa) Atlantis model. Fisken og havet, 2-2016. 112 pp.

Hilborn, R., 2007. Managing fisheries is managing people: what has been learned? Fish and Fisheries 8, 285-296.

Horne, P., Kaplan, I., Marshall, K., 2010. Design and parameterization of a spatially explicit ecosystem model of the central California Current. Technical Memo, NMFS-NWFSC104, Dept. of Commerce, NOAA, p. 140.

Hoegh-Guldberg, O. Bruno, J.F., 2010. The impact of climate change on the world's marine ecosystems. Science 328, 1523-1528. 
Hutton, T., Rochester, W., Fulton, E.A., Condie, S., Savina-Rolland, M., Griffiths, S., McLeod, I., Smith, A.D.M., Smith, D.C., 2012. A large-scale connectivity study: a Coral Sea spatially explicit ecosystem model. Presented at the 12th International Coral Reef Symposium, Cairns, Australia.

Hyder, K., Rossberg, A.G., Allen, J.I., Austen, M.C., Barciela, R.M., Bannister, H.J., et al. 2015. Making modelling count - increasing the contribution of shelf-seas community and ecosystem models to policy development and management. Marine Policy 61, 291-302. doi:http://dx.doi.org/10.1016/j.marpol.2015.07.015.

McCauley, D.J., Pinsky, M.L., Palumbi, S.R., Estes, J.A., Joyce, F.H., Warner, R.R., 2015. Marine defaunation: Animal loss in the global ocean. Science 347, 1255641.

Mullon, C., Steinmetz, F., Merino, G., Fernandes, J.A., Cheung, W.W.L., Butenschön, M., et al., 2016. Quantitative pathways for Northeast Atlantic fisheries based on climate, ecological-economic and governance modelling scenarios. Ecological Modelling 320, 273-91. doi:http://dx.doi.org/10.1016/j.ecolmodel.2015.09.027.

Pikitch, E., Santora, E., Babcock, A., Bakun, A., Bonfil, R., Conover, D.O., Dayton, P., Doukakis, P., Fluharty, D., Heheman, B., Houde, E.D., Link, J.S., Livingston, P.A., Mangel, M., McAllister, M.K., Pope, J., Sainsbury, K.J., 2004. Ecosystem-based fishery management. Science 305, 346-347.

Sainsbury KJ, Punt AE, Smith ADM. 2000. Design of operational management strategies for achieving fishery ecosystem objectives. ICES Journal of Marine Science 57:731-741.

Skern-Mauritzen, M., Ottersen, G., Handegard, N.O., Huse, H., Dingsør, G.E., Stenseth, N.C., Kjesbu, O.S., 2016. Fish and Fisheries 17, 165-175

Weijerman M, Fulton EA, Kaplan IC, Gorton R, Leemans R, Mooij WM, Brainard RE. 2015. An Integrated Coral Reef Ecosystem Model to Support Resource Management under a Changing Climate. PLoS ONE 10(12):e0144165. doi: 10.1371/journal.pone.0144165. 